\title{
Child maltreatment: a survey of dentists in southern Brazil
}

\section{Marina Sousa Azevedo(a) \\ Marília Leão Goettems ${ }^{(a)}$ \\ Adão Brito(a) \\ Anna Paula Possebon ${ }^{(a)}$ \\ Juliana Domingues ${ }^{(a)}$ \\ Flávio Fernando Demarco(b) \\ Dione Dias Torriani(c)}

(a) Graduate Program in Dentistry, School of Dentistry, Federal University of Pelotas, Pelotas, RS, Brazil.

(b) Department of Operative Dentistry, School of Dentistry, Federal University of Pelotas, Pelotas, RS, Brazil.

(c) Department of Social and Preventive Dentistry, School of Dentistry, Federal University of Pelotas, Pelotas, RS, Brazil.

Declaration of Interests: The authors certify that they have no commercial or associative interest that represents a conflict of interest in connection with the manuscript.

Corresponding author:

Dione Dias Torriani

E-mail:dionedt@gmail.com

Received for publication on Aug 23, 2011 Accepted for publication on Nov 16, 2011
Abstract: Child abuse is a serious public health problem and affects the victims' physical and mental health and development. The aims of this study were two-fold: to assess the attitudes and perceptions of dentists regarding child abuse, and to investigate professional characteristics associated with the identification of suspected child abuse. A questionnaire was sent to the 276 dentists of Pelotas, RS, Brazil, and 187 (68.0\%) were returned. Demographic characteristics and profiles of the dentists, and information about their knowledge and attitudes regarding child abuse were collected. Descriptive analysis was performed, and associations were tested by chi-square and Fisher's exact tests. From all dentists surveyed, $123(71.9 \%)$ reported providing treatment for children. Most dentists believed they could detect cases of child abuse (78.7\%), but $85.7 \%$ had never suspected it. Among those who did suspect, $76.0 \%$ did not report the cases to authorities. No differences were observed between sexes, years of graduation, types of licenses, and the frequency at which children were treated. A higher proportion of dentists working at university had suspected child abuse. Even though dentists considered themselves able to identify suspicious cases, only a small percentage reported those suspicions, indicating a lack of awareness by these professionals in the adoption of protective measures for victims of aggression. It is necessary that dental professionals receive interdisciplinary training to enhance their ability to care for and protect children.

Descriptors: Child Abuse; Violence; Child; Dentistry.

\section{Introduction}

Child maltreatment, sometimes referred to as child abuse and neglect, includes all forms of physical and emotional ill-treatment, sexual abuse, neglect, and exploitation that result in actual or potential harm to a child's health, development, or dignity. Within this broad definition, five subtypes can be distinguished:

- physical abuse,

- sexual abuse,

- neglect and negligent treatment,

- emotional abuse, and

- exploitation. ${ }^{1}$

Abuse is an act of commission, whereas child neglect is an act of omission. 
Every child has the right to health and a life free from violence. Each year, however, millions of children around the world are the victims of and witnesses to physical, sexual, and emotional violence. Child maltreatment is a huge global problem, with a serious impact not only on the victims' physical and mental health, well-being, and development throughout their lives, but also, by extension, on society in general. ${ }^{1}$

In Brazil, the maltreatment of children and adolescents has been recognized as a serious public health problem. In a recent review addressing child neglect and abuse by parents, the authors verified that the number of incidents of psychological and physical violence is still high. The prevalence of physical abuse in the studies published in the last 15 years was $15.7 \% .^{2}$

Dentists are in an ideal position to help detect signs of child abuse and should be able to recognize those signs. Statistics have shown that as many as $50 \%$ to $75 \%$ of all cases of child abuse include trauma to the mouth, face, and head. ${ }^{3,4}$ Despite the obligation to report suspected cases, however, dental health professionals continue to under-report child abuse, although awareness of their potential role in detecting this crime is growing. ${ }^{5-8}$

Therefore, the aims of this study were to assess the attitudes and perceptions of dentists regarding child abuse, and to investigate professional characteristics associated with the identification of suspected child abuse.

\section{Methodology Population and settings}

This cross-sectional study was approved by the Human Research Ethics Committee of the Federal University of Pelotas (116/2009). Pelotas is a southern Brazilian city and has nearly 327.000 inhabitants. ${ }^{9}$ A list of all dentists practicing in the city in 2009 was obtained from the local Board of Dentistry. Those whose data were complete (address and telephone number) were eligible to be included $(\mathrm{n}=276)$.

Dental students distributed the questionnaires at the addresses listed, between March and July. All practitioners received an explanation of the study and were given the opportunity to ask questions. If the professional agreed to participate in the study, the survey was completed, and the student returned after a week to collect the questionnaire and the signed informed consent.

\section{Questionnaire}

A previously tested self-administered questionnaire consisting of 48 close-ended items with response options organized vertically was used for data collection.

In the present study, variables regarding demographic characteristics (sex, age), professional data (workplace, number of years of professional activity, and specialization level), and attitudes toward treatment of children with primary dentition (if the dentist provided treatment for children) were used. Information about knowledge and attitudes regarding child abuse was collected. Dentists were asked if they had suspected child abuse and neglect. In the case of a positive answer, they were asked if they had reported the case; in the case of a negative answer, they were asked if they believed they could recognize child abuse. "Workplace" was defined as public, private, both, or Dental School. "Years of dental practice" was categorized into four groups:

- fewer than 10 years,

- 10 to 20 years,

- 21 to 30 years, and

- 30 or more years.

The type of license was classified as:

- general practitioner,

- pediatric dentistry, or

- other specialty.

\section{Data analysis}

Questionnaire responses were tabulated, and percent frequency distributions for responses to each item were computed. Chi-square test and Fisher's exact test were used to analyze two categorical or nominal variables. Data were analyzed with Stata 10.0 (Stata Corporation, College Station, USA). The level of significance was set at $\alpha=0.05$. 


\section{Results}

Of the 276 surveys delivered, 187 surveys were returned, for a response rate of $68 \%$. The majority of dentists surveyed were female $(52.4 \%)$, and $96.0 \%$ considered themselves as being white. Around $66 \%$ of the dentists worked in private practice. Nearly $46 \%$ had up to 10 years of dental practice. Almost $2 / 3$ of the dentists were specialists $(63.7 \%)$, eight of whom were pediatric dentists. Generally, $123(71.9 \%)$ provided dental treatment for children (Table 1).

Most dentists believed they could detect cases of child abuse $(78.7 \%)$. When asked if they had already suspected child abuse, $85.7 \%$ reported that this had never occurred. Among those who did suspect, $76.0 \%$ did not report the case to legal authorities (Table 2).

No differences were observed between sexes, years of graduation, types of licenses, and the frequency at which children were treated in the office. A statistically higher proportion of dentists working at university had suspected cases of child abuse (Table 3).

\section{Discussion}

This study used a self-report questionnaire to obtain information from dentists about their attitudes and perceptions regarding child maltreatment. The representative sample and the high response rate achieved allow for a valid assessment. This method is widely used in cross-sectional study designs where all data can be collected at one point in time, thus avoiding any possible interviewer interference. Also, our study ensured the confidentiality of the questionnaires, which allowed for more confidence in the replies and may have contributed to the high response rate. Other surveys with similar methodology had a lower response rate. ${ }^{10,11}$

Abuse or neglect may present to the dental team in many ways:

- (a) through a direct allegation made by the child, a parent, or some other person;

- (b) through signs and symptoms which are suggestive of physical abuse or neglect; and/or

- (c) through observations of child behavior or parent-child interaction. ${ }^{12}$
Table 1 - Demographic characteristics and profiles of dental practices in Pelotas, Brazil, 2009 ( $n=187$ ).

\begin{tabular}{|c|c|}
\hline Variables & n (\%) \\
\hline \multicolumn{2}{|l|}{ Sex } \\
\hline - Male & $89(47.6)$ \\
\hline - Female & $98(52.4)$ \\
\hline \multicolumn{2}{|l|}{ Years of dental practice } \\
\hline - Up to 10 & $84(45.4)$ \\
\hline$\cdot 11-20$ & $43(23.2)$ \\
\hline - 21-30 & $28(15.1)$ \\
\hline - More than 30 & $30(16.2)$ \\
\hline \multicolumn{2}{|l|}{ Type of license } \\
\hline - General practitioner & $66(36.3)$ \\
\hline - Specialist & $116(63.7)$ \\
\hline \multicolumn{2}{|l|}{ Practice location } \\
\hline - Private & $121(66.1)$ \\
\hline - Public & $17 \quad(9.3)$ \\
\hline - Both (Private/Public) & $22(12.0)$ \\
\hline - Dental School & $23(12.6)$ \\
\hline \multicolumn{2}{|l|}{ Dental attendance of children } \\
\hline - No, parents do not seek & $8 \quad(4.7)$ \\
\hline - No, prefer to refer to others & $40(23.3)$ \\
\hline - Yes, less than once a month & $30(17.5)$ \\
\hline - Yes, at least once a month & $31(18.1)$ \\
\hline - Yes, at least once a week & $38(22.2)$ \\
\hline - Yes, at least once a day & $24(14.0)$ \\
\hline
\end{tabular}

Table 2 - Dentists' attitudes and perceptions about child abuse. Pelotas, Brazil, 2009 ( $n=175$ ).

\begin{tabular}{|c|c|c|}
\hline \multirow{2}{*}{ Questionnaire items } & \multicolumn{2}{|c|}{ Number of dentists (\%) } \\
\hline & Yes & No \\
\hline $\begin{array}{l}\text { Have you ever recognized a } \\
\text { suspicious case of child abuse or } \\
\text { neglect in your dental office? }\end{array}$ & $25(14.3)$ & $150(85.7)$ \\
\hline If yes, did you report it? & $6(24.0)$ & 19 (76.0) \\
\hline $\begin{array}{l}\text { If no, do you believe you are able to } \\
\text { recognize a suspicious case? }\end{array}$ & $118(78.7)$ & 32 (21.3) \\
\hline
\end{tabular}

Dentists who treat children regularly are more likely to attend a victim of abuse, since half of all victims are under 7 years of age. ${ }^{13}$ Of the Pelotas dentists surveyed, 123 reported seeing children in their offices. Among the dentists included, those 
Table 3 - Factors associated with previous suspicions of child abuse, Pelotas, 2009 ( $n=175)$.

\begin{tabular}{|c|c|c|c|}
\hline \multirow{3}{*}{ Variable } & \multicolumn{2}{|c|}{$\begin{array}{l}\text { Recognized a } \\
\text { suspicious case }\end{array}$} & \multirow{3}{*}{$\mathrm{p}$} \\
\hline & Yes & No & \\
\hline & n (\%) & n (\%) & \\
\hline \multicolumn{4}{|l|}{ Sex } \\
\hline - Male & $16(19.5)$ & $66(80.5)$ & \multirow{2}{*}{$0.06^{*}$} \\
\hline - Female & $9 \quad(9.7)$ & $84(90.3)$ & \\
\hline \multicolumn{4}{|l|}{ Years of practice } \\
\hline - Up to 10 & $10(12.0)$ & $73(88.0)$ & \multirow{4}{*}{$0.58 \#$} \\
\hline$\cdot 11-20$ & 7 (16.2) & $36(83.7)$ & \\
\hline - $21-30$ & $5(21.7)$ & $18(78.3)$ & \\
\hline - More than 30 & $3(12.5)$ & $21(87.5)$ & \\
\hline \multicolumn{4}{|l|}{ Practice location } \\
\hline - Private & $10(8.9)$ & $102(91.1)$ & \multirow{4}{*}{$0.008 \#$} \\
\hline - Public & $3(17.7)$ & $14(82.4)$ & \\
\hline - Both (Private/Public) & $4(19.1)$ & 17 (80.9) & \\
\hline - Dental School & $8(36.4)$ & $14(63.6)$ & \\
\hline \multicolumn{4}{|l|}{ Type of license } \\
\hline - Pediatric Dentistry & 3 (33.3) & $6(66.7)$ & \multirow{2}{*}{$0.12 \#$} \\
\hline - General practitioner/others & $22(13.7)$ & $139(86.3)$ & \\
\hline \multicolumn{4}{|c|}{ Frequency of dental attendance of children } \\
\hline - Once a month or less & $5 \quad(8.3)$ & $55(91.7)$ & \multirow{2}{*}{$0.07^{*}$} \\
\hline - More than once a month & $12(19.7)$ & $49(80.3)$ & \\
\hline
\end{tabular}

* chi-square test; \# Fisher's exact test.

who attended children more than once a month, pediatric dentists, males, dentists with 21-30 years of practice, and those working at dental school suspected child maltreatment more frequently. However, there was a statistically significant difference only for the practice location. It is possible that this difference is due to the fact that dentists in a university see a higher number of patients and are trained to deal properly with this issue.

The majority of the dentists believed they could detect cases of child maltreatment $(78.7 \%)$. Similar results were found in a northeastern Brazilian city, where $65 \%$ of the dentists considered themselves capable of such a diagnosis. ${ }^{14}$ This is an encouraging finding which indicates that they have probably been adequately prepared for this professional task.

However, it is widely believed that abuse is be- ing under-reported by health care professionals, including the dental community. It is worrisome that while dentists are in a position to report suspected child abuse cases, only $24 \%$ of those who suspected child maltreatment had reported it to authorities. ${ }^{15,16}$ A northern Ireland study showed that fewer dentists had recognized and reported suspicious cases of child physical abuse throughout their professional life compared with other health professionals. ${ }^{17}$ Although parents or guardians avoid returning to the same physician or emergency room to obtain treatment for an abused child, they do not seem to avoid repeat visits to the same dental care providers. Therefore, it is surprising that dental professionals account for only a small percentage of reports of child abuse and neglect. ${ }^{16}$

Under-reporting of child abuse is a significant problem in the dental profession. In a survey of 2,005 California dentists, $16 \%$ had suspected a case of child abuse or neglect in the preceding 5 years, with only $6 \%$ of the respondents actually reporting a case to authorities. ${ }^{16}$ In a study conducted in two Brazilian cities, $52.9 \%$ of the pediatric dentists had seen a suspicious child physical abuse case; however, only $14.3 \%$ had reported to the authorities. ${ }^{18}$ Only one study found that most suspected cases were reported (89.0). ${ }^{14}$

There are different reasons for dentists' hesitancy to report suspected cases. In the Bsoul et al. ${ }^{6}$ study, the respondents indicated that their major reason for hesitating to report was the lack of adequate patient history. According to the authors, perhaps dentists need to be better informed about how to recognize and gather information to explain children's physical wounds or emotional behaviors. Other reasons cited were the lack of adequate knowledge about abuse, and about the dentists' role in reporting the case. These findings highlight the need for mandatory training in the recognition and reporting of child abuse.

Jordanian dental professionals reported that the main factors influencing their decision to report cases of suspected child abuse were:

- lack of history (76\%),

- uncertainty about diagnosis (73\%), and

- possible consequences to the child (66\%). 
Other influencing factors cited by almost half of the dentists included:

- effects on the child's family,

- concerns about confidentiality,

- hostility of Jordanian families, and

- the uncertainty about the consequences of reporting.

Effect on work and fear of litigation were reported by less than one-third of the dentists. The least-reported factor was the belief that "it is not the dentist's responsibility" (22\%). ${ }^{19}$ In the study by Kilpatrick et al., the main reason given by the dental practitioners was concern about confidentiality. ${ }^{15}$ This apparent reluctance to act on their suspicions suggests the existence of social and psychological barriers to the reporting of child abuse or neglect. ${ }^{16}$

In 1990, an important milestone was the approval of "The child and the adolescent statute", when the notification of suspicious cases of domestic violence became mandatory in Brazil. Health professionals have become responsible for reporting and preventing these cases, while the health system must offer medical and psychosocial assistance for confirmed cases. ${ }^{2}$ Thus, while dentists have a legal and ethical obligation to identify child abuse and neglect and make the appropriate referrals, few know that the law grants professionals immunity from civil or criminal liability when they make a good-faith report. Despite the legal requirements for reporting child abuse or neglect in Brazil, few reports had been made by the dentists included in this survey.

Child abuse has been included in the curriculum framework of Brazilian dental schools, as already occurs in the United Sates, to qualify dentists (and future pediatric dentists) in the diagnosis, treatment, and official reporting of these cases. In the local dental school, this theme is addressed in the discipline of Pediatric Dentistry. In addition to a focus on essential competencies, an interdisciplinary approach to tackling this issue is also important, ${ }^{20}$ since training professionals in the field of child abuse and neglect requires an understanding of the various disciplines involved. Cooperation with specialists from related disciplines ${ }^{21}$ is also important and should be stimulated, because an interdisciplinary approach may help in eliminating the confusion, delays, and poor decision-making caused by professionals unprepared to interact with one another.

The low number of suspicious cases may also be attributed to a lack of dentists' awareness about dental neglect, the most frequent type of abuse that may be seen in a dental office. ${ }^{22}$ Dental neglect is defined by the American Academy of Pediatric Dentistry as the "willful failure of parent or guardian to seek and follow through with treatment necessary to ensure a level of oral health essential for adequate function and freedom from pain and infection." Dental caries, periodontal diseases, and other oral conditions, if left untreated, can lead to pain, infection, and loss of function. It is worth mentioning that since many families face challenges in their attempts to access dental care or acquire insurance for their children, the clinician should determine whether dental services are readily available and accessible to the child when considering whether negligence has occurred. ${ }^{23}$ Lack of access to dental treatment for children has been well-documented in Brazil; thus, this factor must be taken into account. ${ }^{24}$ Even though public access to dental treatment has expanded to larger segments of the Brazilian population, this young population ( $0-5$ years) is underserved in terms of public dental services. ${ }^{25}$ Thus, the dentist must consider his patients' financial, intellectual, and social situation before making a final diagnosis. ${ }^{7}$

In spite of its importance, it is recognized that few dentists know that a parent or guardian could be charged with child neglect for failure to follow through with dental treatment after being informed that a child had rampant caries. ${ }^{16}$ In the study by John et al., only $20 \%$ of all dentists interviewed identified neglect as a form of abuse. ${ }^{26}$ Considering the importance of a healthy dentition in digestion, knowing the role of primary dentition in tooth exchange, and being aware of the consequences of infections and toothaches in the child's social life, dentists have a clear duty to detect and treat cases of neglect. ${ }^{22}$ Adequate qualification of dental professionals is required for the clinical treatment of the victim, as well as for the early detection of the ag- 
gression and notification of legal authorities. ${ }^{27}$

\section{Conclusion}

Even though dentists considered themselves able to identify cases of children maltreatment, among those who were suspicious, only a small percentage referred cases to legal authorities. This indicates a

\section{References}

1. World Health Organization and International Society for Prevention of Child Abuse and Neglect. Preventing child maltreatment: a guide to taking action and generating evidence. 2006 . [citado em 10 mai. 2011]. Disponível em: http://whqlibdoc. who.int/publications/2006/9241594365_eng.pdf.

2. Reichenheim ME, de Souza ER, Moraes CL, de Mello Jorge MH, da Silva CM, de Souza Minayo MC. Violence and injuries in Brazil: the effect, progress made, and challenges ahead. Lancet. 2011 Jun 4;377(9781):1962-75. Epub 2011 May 9.

3. Cairns AM, Mok JY, Welbury RR. The dental practitioner and child protection in Scotland. Br Dent J. 2005 Oct;199(8):51720.

4. Cavalcanti AL. Prevalence and characteristics of injuries to the head and orofacial region in physically abused children and adolescents--a retrospective study in a city of the Northeast of Brazil. Dent Traumatol. 2010 Apr;26(2):149-53.

5. Becker DB, Needleman HL, Kotelchuck M. Child abuse and dentistry: orofacial trauma and its recognition by dentists. J Am Dent Assoc. 1978 Jul;97(1):24-8.

6. Bsoul SA, Flint DJ, Dove SB, Senn DR, Alder ME. Reporting of child abuse: a follow-up survey of Texas dentists. Pediatr Dent. 2003 Nov-Dec;25(6):541-5.

7. Jessee SA. Risk factors as determinants of dental neglect in children. ASDC J Dent Child. 1998 Jan-Feb;65(1):17-20.

8. Needleman HL. Orofacial trauma in child abuse: types, prevalence, management, and the dental profession's involvement. Pediatr Dent. 1986 May;8(1 Spec No):71-80.

9. Instituto Brasileiro de Geografia e Estatística. Estimativas de População. 2009. [citado em 14 Ago 2009]. Disponível em: http://www.ibge.gov.br/home/estatistica/populacao/estimativa2009/POP2009_DOU.pdf.

10. Brickhouse TH, Unkel JH, Kancitis I, Best AM, Davis RD. Infant oral health care: a survey of general dentists, pediatric dentists, and pediatricians in Virginia. Pediatr Dent. 2008 Mar-Apr;30(2):147-53.

11. Splieth CH, Bunger B, Pine C. Barriers for dental treatment of primary teeth in East and West Germany. Int J Paediatr Dent. 2009 Mar;19(2):84-90.

12. Sidebotham PD, Harris JC. Protecting children. Br Dent J. 2007 Apr;202(7):422-3. lack of awareness by these professionals about the adoption of protective measures for victims of aggression. It is necessary that professionals receive more information on the need to be alert to the detection of suspected cases of maltreatment of children and adolescents, and on their legal duty to report such cases to authorities.

13. Persaud DI, Squires J. Abuse detection in the dental environment. Quintessence Int. 1998 Jul;29(7):459-68.

14. Granville-Garcia AF, de Menezes VA, Silva PFRM. Maustratos infantis: Percepção e responsabilidade do cirurgiãodentista. Rev Odonto Cien. 2008 Jan-Mar;23(1):35-9.

15. Kilpatrick NM, Scott J, Robinson S. Child protection: a survey of experience and knowledge within the dental profession of New South Wales, Australia. Int J Paediatr Dent. 1999 Sep;9(3):153-9.

16. Ramos-Gomez F, Rothman D, Blain S. Knowledge and attitudes among California dental care providers regarding child abuse and neglect. J Am Dent Assoc. 1998 Mar;129(3):340-8.

17. Lazenbatt A, Freeman R. Recognizing and reporting child physical abuse: a survey of primary healthcare professionals. J Adv Nurs. 2006 Nov;56(3):227-36.

18. Santos JF, Nunes KS, Cavalcanti AL, Silva EC. Maus-tratos infantis: conhecimento e atitudes de Odontopediatras em Uberlândia e Araguari, Minas gerais. Pesqui Bras Odontopediatria Clin Integr. 2006 Set-Dez;6(3):273-9.

19. Owais AI, Qudeimat MA, Qodceih S. Dentists' involvement in identification and reporting of child physical abuse: Jordan as a case study. Int J Paediatr Dent. 2009 Jul;19(4):291-6.

20. Champion KM, Shipman K, Bonner BL, Hensley L, Howe AC. Child maltreatment training in doctoral programs in clinical, counseling, and school psychology: where do we go from here? Child Maltreat. 2003 Aug;8(3):211-7.

21. Pabiś M, Wrońska I, Slusarska B, Cuber T. Paediatric nurses’ identification of violence against children. J Adv Nurs. 2011 Feb;67(2):384-93.

22. Kiran K, Kamala BK. Child abuse and the role of a dental professional-The Indian scenario. Child Abuse Negl. 2011 Mar;35(3):157-8.

23. American Academy of Pediatrics Committee on Early Childhood, Adoption, and Dependent Care: Oral and dental aspects of child abuse and neglect. Pediatrics. 1986 Sep;78(3):537-9.

24. Camargo MB, Dumith SC, Barros AJ. [Regular use of dental care services by adults: patterns of utilization and types of services]. Cad Saude Publica. 2009 Sep;25(9):1894-906. Portuguese.

25. Pucca GA, Costa JF, Chagas L e D, Sivestre RM. Oral health policies in Brazil. Braz Oral Res. 2009 Jun;23 Suppl 1:9-16. 
26. John V, Messer LB, Arora R, Fung S, Hatzis E, Nguyen T, et al. Child abuse and dentistry: a study of knowledge and attitudes among dentists in Victoria, Australia. Aust Dent J. 1999 Dec;44(4):259-67.
27. Cavalcanti AL, Granville-Garcia AF, Costa EMM de B, Fontes L de BC, Sá LOPD de, Lemos AD. Dentist's role in recognizing child abuse: a case report. Rev Odonto Cien. 2009 OutDez;24(4):432-4. 